\title{
Comparison of complete renal response and mortality in early- and late-onset lupus nephritis: a multicenter retrospective study of a Japanese cohort
}

Kunihiro Ichinose ${ }^{1 *}$ (D) Mineaki Kitamura ${ }^{2}$, Shuntaro Sato ${ }^{3}$, Keita Fujikawa ${ }^{4}$, Yoshiro Horai ${ }^{5}$, Naoki Matsuoka ${ }^{6}$, Masahiko Tsuboi ${ }^{6}$, Fumiaki Nonaka ${ }^{7}$, Toshimasa Shimizu', Remi Sumiyoshi ${ }^{1}$, Tomohiro Kogaa', Shin-ya Kawashiri', Naoki Iwamoto ${ }^{1}$, Takashi Igawa ${ }^{1}$, Mami Tamai ${ }^{1}$, Hideki Nakamura ${ }^{1}$, Tomoki Origuchi ${ }^{8}$, Tomoya Nishino ${ }^{2}$ and Atsushi Kawakami ${ }^{1}$

\begin{abstract}
Background: Most patients with systemic lupus erythematosus (SLE) progress to lupus nephritis (LN) within 5 years of their SLE diagnosis, although it is not uncommon for $L N$ to develop at later time points. Here we evaluated the clinical features of early- and late-onset LN.
\end{abstract}

Patients and methods: We retrospectively analyzed the cases of 184 of the 201 patients who underwent a renal biopsy at Nagasaki University Hospital and associated community hospitals between 1990 and 2016 and were diagnosed as having $L N$. Early onset was defined as the development of $L N$ within the first 5 years after the patient's SLE diagnosis, and late onset was defined as LN development $>5$ years post-diagnosis. We analyzed the complete renal response (CR) at 6 and 12 months after induction therapy, the classification of renal pathology, and the mortality of the early- and late-onset LN groups.

Results: The mean follow-up duration after the renal biopsy was $123 \pm 85$ months. There were 113 (61.4\%) early-onset patients and 71 (38.6\%) late-onset patients. A multivariate analysis revealed that the following factors were predictive of CR: at 6 months: female sex (odds ratio [OR] 3.93, 95\% confidence interval [CI] 1.31-11.77, $p=0.010$ ), proteinuria (OR $0.83,95 \% \mathrm{Cl} 0.71-0.97, p=0.009$ ), index of activity (0-24) (OR 0.83, 95\% Cl 0.70-0.99, $p=0.030$ ), and early-onset LN (OR $2.39,95 \% \mathrm{Cl} 1.15-4.98, p=0.018$ ); at 12 months: female sex (OR 3.60, 95\% Cl 1.32-9.83, $p=0.013$ ), mixed LN (OR 0.18, $95 \% \mathrm{Cl} 0.04-0.80, p=0.024)$, index of activity (0-24) (OR 0.80,95\% Cl 0.68-0.94, $p=0.007$ ), and early-onset LN (OR 2.10 , $95 \% \mathrm{Cl} 1.05-4.23, p=0.035)$. In a Cox proportional hazards and Fine-Gray regression model, the early-onset LN group had a significantly better mortality rate than the late-onset $L N$ group ( $p=0.038$ and $p=0.043$, respectively).

Conclusions: In our cohort, early-onset LN was a better predictor of CR at 6 and 12 months than late-onset LN. Our results suggest that early-onset LN patients had lower mortality than late-onset LN patients.

Keywords: Complete renal response, Lupus nephritis, Early onset, Late onset, Systemic lupus erythematosus

\footnotetext{
* Correspondence: kichinos@nagasaki-u.ac.jp

'Department of Immunology and Rheumatology, Division of Advanced

Preventive Medical Sciences, Nagasaki University Graduate School of

Biomedical Sciences, 1-7-1 Sakamoto, Nagasaki 852-8501, Japan

Full list of author information is available at the end of the article
}

(c) The Author(s). 2020 Open Access This article is licensed under a Creative Commons Attribution 4.0 International License, which permits use, sharing, adaptation, distribution and reproduction in any medium or format, as long as you give appropriate credit to the original author(s) and the source, provide a link to the Creative Commons licence, and indicate if changes were made. The images or other third party material in this article are included in the article's Creative Commons licence, unless indicated otherwise in a credit line to the material. If material is not included in the article's Creative Commons licence and your intended use is not permitted by statutory regulation or exceeds the permitted use, you will need to obtain permission directly from the copyright holder. To view a copy of this licence, visit http://creativecommons.org/licenses/by/4.0/ The Creative Commons Public Domain Dedication waiver (http://creativecommons.org/publicdomain/zero/1.0/) applies to the data made available in this article, unless otherwise stated in a credit line to the data. 


\section{Introduction}

Systemic lupus erythematosus (SLE) is a chronic multisystem autoimmune disease with a wide range of clinical and immunological manifestations, among which lupus nephritis ( $\mathrm{LN})$ is the most common cause of morbidity and mortality [1]. In fact, between 50 and $60 \%$ of adult SLE patients develop signs and symptoms of kidney disease during their disease course $[2,3]$. The standardized mortality rate of individuals with SLE without $\mathrm{LN}$ is 2.4-fold higher than that for the general population, while the rate for SLE patients with LN is much greater at 6.0-6.8fold higher than that for the general population [4-7]. Although the mortality rate for SLE has declined over the past few decades, up to $20 \%$ of SLE patients who are still affected by LN will develop end-stage kidney disease (ESKD) within the first 10 years of the disease course $[8,9]$.

Most SLE patients who develop LN do so within 5 years of their diagnosis of SLE, but it is not uncommon for SLE patients to develop LN later than that [2]. It has been unclear whether the timing of the onset of LN influences the treatment response and long-term prognosis of the patients. Only a few studies have compared early-onset LN (occurring < 5 years after the diagnosis of SLE) with late-onset LN (occurring $>5$ years post-diagnosis) $[10,11]$. A recent report showed no difference in severity or long-term prognosis between earlyand late-onset LN patients [11]. African and Hispanic patients are known to have worse renal outcomes and mortality than Caucasian patients, and there are differences in prognosis among ethnicities. To the best of our knowledge, no study has compared early-onset and late-onset LN using the abovedescribed definition in an Asian population.

The recommendations for LN management published by the European League Against Rheumatism (EULAR)/ European Renal Association-European Dialysis and Transplant Association (ERA-EDTA) aim for a complete renal response (CR) by 12 months of treatment, but this goal can be extended if nephrotic-range proteinuria is present at baseline [12]. We demonstrated that the survival rate of LN patients was significantly correlated with their attainment of a CR at 12 months after the start of induction therapy [13]. Many poor-prognosis factors for LN have been reported, including age, sex, ethnicity, and histological findings, and we speculated that the prediction of CR attainment at 6 and 12 months of treatment would lead to better renal outcomes and life prognoses [6, 14].

In this study, we determined the predictors of CR attainment after 6 and 12 months of induction therapy, and we examined the relationship between renal outcomes and mortality in early- and late-onset LN patients with biopsyproven LN treated at Nagasaki University Hospital and affiliated community hospitals in Nagasaki, Japan.

\section{Patients and methods}

This was a retrospective observational study comprising a total of 201 patients with biopsy-proven LN treated between 1990 and 2016 at Nagasaki University Hospital and affiliated community hospitals. The diagnosis of SLE in all patients was made by the attending physician according to the 1997 American College of Rheumatology (ACR) criteria [15]. Two expert nephropathologists (M.K. and T.T.) classified the biopsy specimens separately based on the International Society of Nephrology/ Renal Pathology (ISN/RPS) classification to obtain the LN patients' pathological information [16], regardless of the patients' previous World Health Organization (WHO) or ISN/RPS classification. The ISN/RPS class II, III/IV, or $\mathrm{V}$ types were pure types and did not include any other types.

Patients with advanced comorbidities or other diseases associated with impaired renal function (e.g., diabetic or primary renal disease) were excluded. Patients with inadequate medical records and patients with $<12$ months of follow-up were also excluded. All patients were followed up at 1 - to 3 -month intervals and at $\geq 12$ months from the date of their renal biopsy.

We divided the 201 patients into two groups: early-onset LN and late-onset LN. As in previous studies [10,11, 17], early onset was defined as the development of LN within 5 years of the patient's SLE diagnosis, and late onset was defined as the development of $\mathrm{LN}>5$ years after the patient's SLE diagnosis. Some of the patients provided written informed consent for the use of their data, and the opt-out strategy was used by the remainder of the patients. Patients who declined to give informed consent were excluded. The study was reviewed and approved by the Medical Ethics Committee of Nagasaki University Hospital (approval nos. 12012397 and 17082129).

\section{Data collection}

The patients' baseline characteristics were collected on the dates of their renal biopsies. The demographic data included the patient's age at the onset of SLE, sex, duration of SLE (from the diagnosis of SLE to renal biopsy), and comorbidities of Sjögren's syndrome (SS)/anti-phospholipid syndrome (APS) and the induction treatment used. We analyzed the patients' laboratory data, including the white blood cell (WBC) count, lymphocyte count, hemoglobin, platelet counts, albumin, proteinuria, urine protein/creatinine ratio $(\mathrm{Up} / \mathrm{Ucr})$, serum creatinine $(\mathrm{Cr})$, blood urea nitrogen (BUN), and estimated glomerular filtration rate (GFR). Immunological parameters were also measured, including complement 3 (C3), complement 4 (C4), total hemolytic complement (CH50), immunoglobulin (Ig) G, IgA, IgM, anti-nuclear antibody (ANA), anti-doublestranded DNA antibody (anti-dsDNA), anti-Smith (Sm) antibody, and anti-ribonucleoprotein (RNP) antibody. The histological characteristics of the activity and chronicity scores were determined as described previously [18]. We examined the presence or absence of hypertension at the time of renal biopsy. Hypertension was defined as systolic 
blood pressure $\geq 140$ or diastolic blood pressure $\geq 90$ $\mathrm{mmHg}$ on 2 or more occasions.

Treatment and the definition of complete renal remission Based on the clinical judgment of the rheumatologist and the treatment guidelines/recommendations for $\mathrm{LN}$ published by the ACR and the EULAR/ERA-EDTA $[19,20]$, the patient was treated with immunosuppressive agents. Treatment consisted of prednisolone (PSL) with intravenous cyclophosphamide (IVCY; $500-1000 \mathrm{mg} / \mathrm{m}^{2}$ body surface area $1 \times /$ month for 6 months), or PSL in combination with a first-line immunosuppressive regimen used for the treatment of $\mathrm{LN}$, followed by IVCY or oral immunosuppressive agents quarterly; PSL was administered at doses of $0.5-1 \mathrm{mg} / \mathrm{kg} /$ day with or without intravenous methylprednisolone (mPSL) pulse therapy (50-1000 $\mathrm{mg} /$ day $\times 3$ days). Plasma exchange $(\mathrm{PE})$ was performed in patients who were refractory to other treatments.

At the discretion of the attending physician, induction therapy was performed for approx. 6 months. We defined $\mathrm{CR}$ at 6 and 12 months as an Up/Ucr ratio $<50 \mathrm{mg} / \mathrm{mmol}$ (roughly equivalent to proteinuria $<0.5 \mathrm{~g} / 24 \mathrm{~h}$ ) and a normal or near-normal GFR (within $10 \%$ of the patient's normal GFR if previously abnormal). We defined partial renal response (PR) as a normal or near-normal GFR with a $\geq 50 \%$ reduction in proteinuria to subnephrotic levels [19, 21, 22].

\section{Mortality, the occurrence of ESKD, and predictors of CR attainment at 6 and 12 months}

The primary outcome was mortality from any cause in both the early- and late-onset LN groups. The secondary outcome was ESKD, defined as dialysis dependence for $>3$ months. We also determined the predictors of CR attainment at 6 and 12 months after the start of induction therapy. Data were collected until either the patient's last follow-up or until December 31, 2019, whichever was later.

\section{Statistical analyses}

A nonparametric Wilcoxon rank-sum test was used for intergroup comparisons of multiple variables. Fisher's exact test was used to test for possible associations between each variable and the treatment response. We conducted univariate and multivariate regression analysis to determine the predictive factors of clinical response. The above statistical analyses were performed using $\mathrm{JMP}^{\circledR}$ Pro15 software (SAS Institute, Cary, NC). Data related to the length of time to ESKD or mortality after induction therapy were analyzed using the 1-KM (Kaplan-Meier estimate) method with a log-rank test. Patients were censored if they were lost to follow-up or reached the end of the study. Kaplan-Meier analyses may overestimate the cumulative incidence if death is censored in the same way as when censoring for other reasons; therefore, the cumulative incidence of ESKD and mortality were also analyzed with death as a competing risk by Gray's test. A Cox proportional hazards and Fine-
Gray regression model were used to examine the risk of ESKD and mortality. These calculations were performed with EZR (Saitama Medical Center, Jichi Medical University, Saitama, Japan), which is a graphical user interface for R (The R Foundation for Statistical Computing, Vienna, Austria) [23]. The significance level was set at $p<0.05$.

\section{Results}

\section{Patient characteristics}

Of the 201 enrolled patients, a total of 184 patients could be followed for therapeutic response at 6 and 12 months after their induction therapy (Fig. 1). The demographic and disease-related features of the 184 patients are summarized in Supplementary Table S1. The majority of the patients were female $(84.8 \%)$. The median age at the onset of LN was 34.0 years (interquartile range [IQR] 24.0-45.0 years), and the disease duration of SLE was 21 months (IQR 1.0-116.0 months). The mean follow-up duration after the renal biopsy was $123 \pm 85$ months. The renal pathology of 99 (53.8\%) patients was classified as ISN/RPS class III or IV, and 41 (22.2\%) patients were classified as ISN/RPS class V. Seventy-seven (43.0\%) patients were treated with intravenous mPSL pulse therapy, 41 (22.9\%) patients were treated with IVCY, and 58 (32.4\%) patients were treated with tacrolimus (TAC) for induction therapy.

We then divided the 184 patients into two groups based on whether they had early-onset or late-onset LN (Table 1): 113 patients (61.4\%) had early-onset LN, and 71 patients $(38.6 \%)$ had late-onset LN. Among the disease-related features at baseline, higher age at SLE

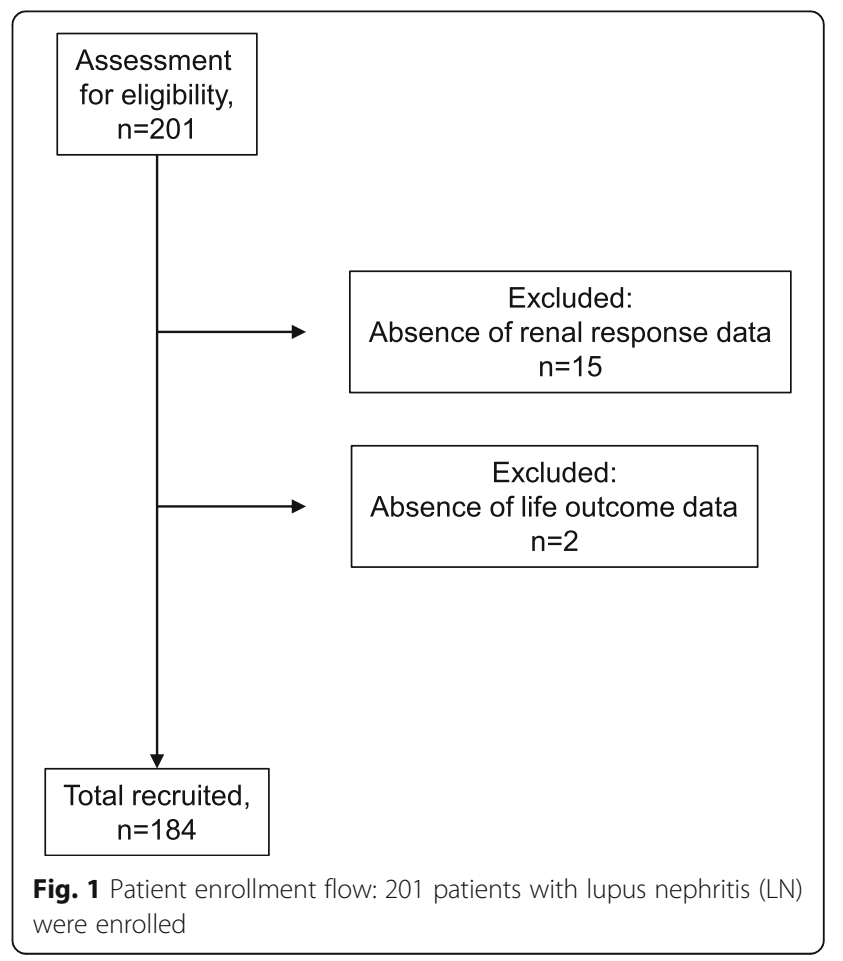


Table 1 Baseline characteristics of the patients

\begin{tabular}{|c|c|c|c|c|c|c|c|c|c|c|c|}
\hline \multirow[t]{2}{*}{ Baseline variables } & \multicolumn{2}{|c|}{$\begin{array}{l}\text { Early-onset LN } \\
(N=113)\end{array}$} & \multicolumn{2}{|c|}{$\begin{array}{l}\text { Late-onset LN } \\
(N=71)\end{array}$} & \multirow[t]{2}{*}{$\begin{array}{l}p \\
\text { value }\end{array}$} & \multirow[t]{2}{*}{ Baseline variables } & \multicolumn{2}{|c|}{$\begin{array}{l}\text { Early-onset LN } \\
(N=113)\end{array}$} & \multicolumn{2}{|c|}{$\begin{array}{l}\text { Late-onset LN } \\
(N=71)\end{array}$} & \multirow[t]{2}{*}{$\begin{array}{l}p \\
\text { value }\end{array}$} \\
\hline & Median & $\mathrm{IQR}$ & Median & $\mathrm{IQR}$ & & & Median & IQR & Median & IQR & \\
\hline Age at SLE onset, years & 32 & $(21-45)$ & 24 & $(16-31)$ & $\begin{array}{l}< \\
0.001^{*}\end{array}$ & $\mathrm{CH} 50$ (mg/dl) & 16.8 & $\begin{array}{l}(10.4- \\
30.0)\end{array}$ & 18.9 & $\begin{array}{l}(14.5- \\
31.2)\end{array}$ & $0.016^{*}$ \\
\hline Age at LN onset, years & 32 & $(22-46)$ & 35 & $(29-44)$ & 0.065 & C3 (mg/dl) & 41.2 & $\begin{array}{l}(28.9- \\
63.4)\end{array}$ & 56.5 & $\begin{array}{l}(40.9- \\
72.5)\end{array}$ & $0.001^{*}$ \\
\hline Sex (\% female) & \multicolumn{2}{|c|}{$92 / 113(81.4)$} & \multicolumn{2}{|c|}{$64 / 71(90.1)$} & 0.141 & C4 (mg/dl) & 8.0 & $\begin{array}{l}(4.3- \\
13.1)\end{array}$ & 10.0 & $\begin{array}{l}(6.1- \\
16.4)\end{array}$ & 0.069 \\
\hline SLE duration, months & 2 & $(0-10)$ & 125 & $(101-197)$ & $\begin{array}{l}< \\
0.001^{*}\end{array}$ & $\begin{array}{l}\text { Comorbidities of SS } \\
(\%)\end{array}$ & \multicolumn{2}{|c|}{ 15/113 (13.3) } & \multicolumn{2}{|c|}{ 7/71 (9.9) } & 0.642 \\
\hline Proteinuria, $\mathrm{g} / \mathrm{gCr}$ & 1.4 & $(0.6-3.8)$ & 2.1 & $(1.0-3.4)$ & 0.199 & $\begin{array}{l}\text { Comorbidities of APS } \\
(\%)\end{array}$ & \multicolumn{2}{|c|}{ 13/113 (11.5) } & \multicolumn{2}{|c|}{$5 / 71(7.0)$} & 0.446 \\
\hline $\begin{array}{l}\text { White blood cell count, } \\
/ \mu \mathrm{l}\end{array}$ & 4700 & $\begin{array}{l}(3720- \\
6800)\end{array}$ & 5800 & $\begin{array}{l}(4560- \\
7725)\end{array}$ & $0.004^{*}$ & ISN/RPS III or IV (\%) & \multicolumn{2}{|c|}{$54 / 113(47.8)$} & \multicolumn{2}{|c|}{$45 / 71(63.4)$} & $0.048^{*}$ \\
\hline Lymphocyte count, / / l & 880 & $\begin{array}{l}(554- \\
1491)\end{array}$ & 918 & $\begin{array}{l}(617- \\
1400)\end{array}$ & 0.998 & ISN/RPS V (\%) & \multicolumn{2}{|c|}{ 24/113 (21.2) } & \multicolumn{2}{|c|}{ 17/71 (23.9) } & 0.717 \\
\hline Hemoglobin, g/dl & 11.0 & $(9.8-12.2)$ & 11.5 & $\begin{array}{l}(10.4- \\
13.1)\end{array}$ & 0.066 & $\begin{array}{l}\text { Index of activity (0- } \\
\text { 24) }\end{array}$ & 5 & $(3-7)$ & 6 & $(4-8)$ & 0.056 \\
\hline Platelet counts, $\times 10^{4} / \mu \mathrm{l}$ & 20.7 & $\begin{array}{l}(14.0- \\
26.1)\end{array}$ & 22.2 & $\begin{array}{l}(17.0- \\
27.7)\end{array}$ & 0.174 & $\begin{array}{l}\text { Index of chronicity } \\
(0-12)\end{array}$ & 2 & $(0-2)$ & 3 & $(2-4)$ & $\begin{array}{l}< \\
0.001^{*}\end{array}$ \\
\hline Albumin, g/dl & 3.2 & $(2.5-3.8)$ & 3.2 & $(2.8-3.8)$ & 0.324 & mPSL pulse (\%) & \multicolumn{2}{|c|}{$60 / 109(55.1)$} & \multicolumn{2}{|c|}{$42 / 70(60.0)$} & 0.539 \\
\hline BUN, mg/dl & 14.2 & $\begin{array}{l}(11.0- \\
20.0)\end{array}$ & 15.5 & $\begin{array}{l}(12.0- \\
21.3)\end{array}$ & 0.504 & TAC (\%) & \multicolumn{2}{|c|}{$30 / 109(27.5)$} & \multicolumn{2}{|c|}{$28 / 70(40.0)$} & 0.102 \\
\hline $\mathrm{Cr}, \mathrm{mg} / \mathrm{dl}$ & 0.7 & $(0.6-1.0)$ & 0.7 & $(0.6-0.9)$ & 0.906 & CyA (\%) & \multicolumn{2}{|c|}{ 11/109 (10.1) } & \multicolumn{2}{|c|}{ 9/70 (12.9) } & 0.630 \\
\hline eGFR, $\mathrm{ml} / \mathrm{min} / 1.73 \mathrm{~m}^{2}$ & 80.6 & $\begin{array}{l}(58.0- \\
102.6)\end{array}$ & 78.8 & $\begin{array}{l}(57.7- \\
97.6)\end{array}$ & 0.560 & AZP (\%) & \multicolumn{2}{|c|}{ 2/109 (1.8) } & \multicolumn{2}{|c|}{$2 / 70(2.9)$} & 0.645 \\
\hline ANA & 640 & $\begin{array}{l}(175- \\
1280)\end{array}$ & 320 & $(80-640)$ & $\begin{array}{l}< \\
0.001^{*}\end{array}$ & MZR (\%) & \multicolumn{2}{|c|}{ 28/109 (25.7) } & \multicolumn{2}{|c|}{$18 / 70(25.7)$} & 1.000 \\
\hline $\begin{array}{l}\text { Anti-ds-DNA antibodies, } \\
\mathrm{U} / \mathrm{ml}\end{array}$ & 50.8 & $\begin{array}{l}(12.1- \\
300.0)\end{array}$ & 20.8 & $(5.1-71.7)$ & $\begin{array}{l}< \\
0.001^{*}\end{array}$ & IVCY (\%) & \multicolumn{2}{|c|}{ 24/109 (22.0) } & \multicolumn{2}{|c|}{$17 / 70(24.3)$} & 0.720 \\
\hline $\begin{array}{l}\text { Anti-RNP antibodies, U/ } \\
\mathrm{ml}\end{array}$ & 8.7 & $(4.2-98.5)$ & 8.8 & $(2.4-86.2)$ & 0.403 & MMF (\%) & \multicolumn{2}{|c|}{$4 / 109(3.7)$} & \multicolumn{2}{|c|}{$5 / 70(7.1)$} & 0.316 \\
\hline Anti-Sm antibodies, $\mathrm{U} / \mathrm{ml}$ & 8.7 & $(2.3-88.2)$ & 4.4 & $(1.0-28.9)$ & 0.095 & PE (\%) & 9/109 (8. & & $5 / 70(7$. & & 1.000 \\
\hline $\operatorname{lgG}, \mathrm{mg} / \mathrm{dl}$ & 1750 & $\begin{array}{l}(1327- \\
2190)\end{array}$ & 1150 & $\begin{array}{l}(801- \\
1482)\end{array}$ & $\begin{array}{l}< \\
0.001 *\end{array}$ & Hypertension (\%) & $43 / 110$ & (39.1) & $27 / 68$ & 9.7) & 1.000 \\
\hline $\lg A, \mathrm{mg} / \mathrm{dl}$ & 271 & $(196-369)$ & 274 & $(188-369)$ & 0.371 & Biopsy before 2002 & $52 / 113$ & $(46.0)$ & $28 / 71(3$ & 9.4) & 0.446 \\
\hline lgM, mg/dl & 114.0 & $\begin{array}{l}(75.2- \\
175.0)\end{array}$ & 27.1 & $\begin{array}{l}(45.8- \\
142.3)\end{array}$ & $\begin{array}{l}< \\
0.001^{*}\end{array}$ & & & & & & \\
\hline
\end{tabular}

${ }^{*} p<0.05$. $p$ values were determined by nonparametric Wilcoxon rank-sum test and Fisher's exact test. IQR interquartile range

onset $(p<0.001)$, a lower WBC count $(p=0.004)$, a higher ANA titer $(p<0.001)$, an elevated anti-ds-DNA antibody titer $(p<0.001)$, higher IgG and IgM levels ( $\mathrm{p}<$ $0.001)$, lower CH50 $(p=0.016)$ and C3 $(p=0.001)$ levels, a lower prevalence of ISN/RPS class III or IV $(p=0.048)$, and a lower index of chronicity $(0-12)(p<0.001)$ were significantly related to early-onset LN.

\section{Differences in the ISN/RPS classification between early- onset and late-onset $\mathrm{LN}$}

There were significantly more patients with pure class II nephritis in the early-onset LN group $(p<0.05)$ (Fig. 2), whereas class III or IV (III/IV) (Table 1) and mixed classes III $+\mathrm{V}$ and IV $+\mathrm{V}$ LN were significantly more prevalent in the late-onset LN group $(p<0.05)$ (Fig. 2). The prevalences of pure classes I, III, IV, V, and VI were not significantly different between the early- and late-onset groups.

\section{Predictors of CR at 6 months and 12 months after induction therapy}

The predictors of a CR at 6 and 12 months after induction therapy in the univariate and multivariate analyses are shown in Tables 2 and 3, respectively. In the multivariate regression analysis, the independent predictors of a $\mathrm{CR}$ at 


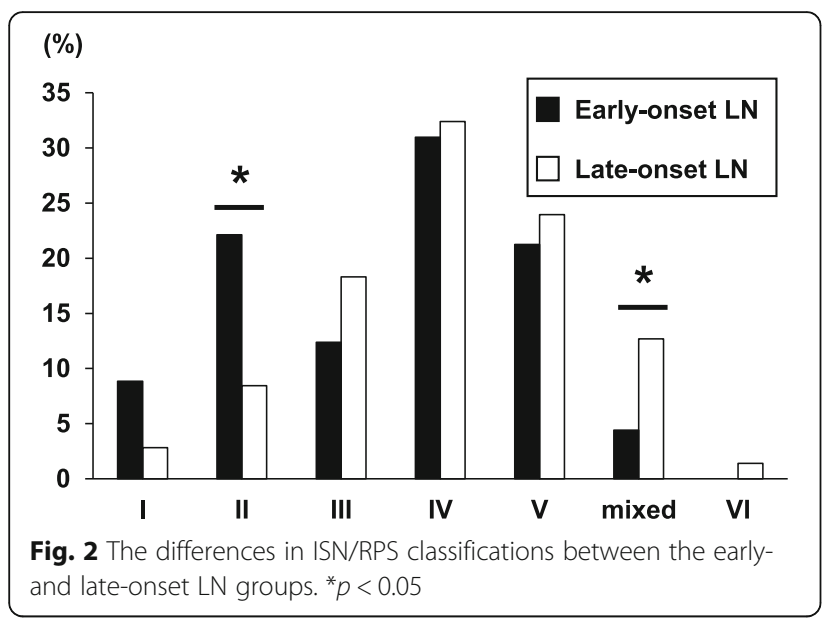

6 months after induction therapy were female sex (odds ratio [OR] 3.93, 95\% confidence interval [CI] 1.31-11.77, $p=0.010$ ), proteinuria ( $\mathrm{g} / \mathrm{gCr}$ ) (OR $0.83,95 \%$ CI $0.71-$ $0.97, p=0.009)$, index of activity (0-24) (OR $0.83,95 \% \mathrm{CI}$ $0.70-0.99, p=0.030$ ), and early-onset LN (OR 2.39, 95\% CI 1.15-4.98, $p=0.018)$. The independent predictors of a $\mathrm{CR}$ at 12 months after induction therapy were female sex (OR 3.60, 95\% CI 1.32-9.83, $p=0.013$ ), mixed LN (OR $0.18,95 \%$ CI $0.04-0.80, p=0.024)$, index of activity $(0-24)$ (OR 0.80, 95\% CI 0.68-0.94, $p=0.007$ ), and early-onset LN (OR 2.10, 95\% CI 1.05-4.23, $p=0.035$ ).

\section{The renal survival rate and survival rate: early-onset vs. late-onset $\mathrm{LN}$}

Seven patients (3.8\%) progressed to ESKD, and nine patients $(4.9 \%)$ died during the observation period. The 1$K M$ (Kaplan-Meier analysis estimate) and competing risk analysis showed that the cumulative incidence of ESKD was not significantly different between the early-onset LN group and late-onset LN group ( $p=0.725$ and $p=$ 0.575 , respectively) (Fig. 3), whereas the cumulative incidence of mortality differed significantly between the early- and late-onset LN groups $(p=0.031$ and $p=0.040$, respectively) (Fig. 4).

\section{The hazard risk of ESKD and mortality}

In both the Cox and Fine-Gray regression models, the hazard ratio (HR) for ESKD in the early-onset LN group was not significantly different from that in the late-onset group. In contrast, the HR for mortality in the earlyonset group was significantly lower than that in the lateonset group (Table 4). The result did not change when death was included in the cumulative incidence or FineGray regression analysis as competing risk.

\section{Discussion}

The results of our analyses demonstrated that early-onset $\mathrm{LN}$ was a predictor of CR attainment at 6 and 12 months of treatment. Several studies have indicated that patients with $\mathrm{LN}$ who attain a CR have a better survival rate than those who do not attain a CR [13,24, 25]. We thus speculated that patients with early-onset $\mathrm{LN}$ would have a better mortality rate than those with late-onset LN.

Several studies compared the clinical characteristics of early-onset versus late-onset $\mathrm{LN}$ and their association with long-term prognosis. The studies' conclusions varied and are controversial; Varela et al. compared early-onset and late-onset LN and reported no significant difference in nephritis development or histological type [10], and Ugolini-Lopes et al. observed no differences in serum $\mathrm{Cr}$ levels or the prevalence of ESKD or mortality after 7 years of follow-up [11]. A recent investigation comparing the disease profiles and outcomes of early-onset and late-onset LN patients did not reveal any significant differences [17]. However, these reports lack treatment information and clinicopathological considerations (including the index of activity and chronicity), which are study limitations.

In Japan, a study comparing early- and late-onset LN in a cohort other than ours was reported [26]; its

Table 2 Multivariate regression model of factors predictive of achieving a complete renal response at 6 months

\begin{tabular}{|c|c|c|c|c|c|c|}
\hline \multirow[b]{2}{*}{ Parameter } & \multicolumn{3}{|c|}{ Univariate } & \multicolumn{3}{|c|}{ Multivariate } \\
\hline & OR & $95 \% \mathrm{Cl}$ & $\boldsymbol{p}$ value & OR & $95 \% \mathrm{Cl}$ & $\boldsymbol{p}$ value \\
\hline Sex (\% female) & 3.67 & $1.41-9.54$ & $0.004^{*}$ & 3.93 & $1.31-11.77$ & $0.010^{*}$ \\
\hline ISN/RPS III or IV, \% & 0.40 & $0.22-0.73$ & $0.002^{*}$ & 1.43 & $0.58-3.51$ & 0.439 \\
\hline Mixed LN & 0.64 & $0.21-1.99$ & 0.433 & - & - & - \\
\hline $\mathrm{Cr}, \mathrm{mg} / \mathrm{dl}$ & 0.42 & $0.19-0.91$ & $0.011^{*}$ & 0.93 & $0.45-1.90$ & 0.838 \\
\hline Proteinuria, $\mathrm{g} / \mathrm{gCr}$ & 0.77 & $0.66-0.90$ & $<0.001^{*}$ & 0.83 & $0.71-0.97$ & $0.009^{*}$ \\
\hline Index of activity (0-24) & 0.79 & $0.70-0.89$ & $<0.001^{*}$ & 0.83 & $0.70-0.99$ & $0.030^{*}$ \\
\hline Hypertension & 0.31 & $0.16-0.59$ & $<0.001^{*}$ & 0.65 & $0.30-1.41$ & 0.279 \\
\hline Early-onset LN & 2.01 & $1.09-3.70$ & $0.024^{*}$ & 2.39 & $1.15-4.98$ & $0.018^{*}$ \\
\hline
\end{tabular}


Table 3 Multivariate regression model of factors predictive of achieving a complete renal response at 12 months

\begin{tabular}{|c|c|c|c|c|c|c|}
\hline \multirow[b]{2}{*}{ Parameter } & \multicolumn{3}{|c|}{ Univariate } & \multicolumn{3}{|c|}{ Multivariate } \\
\hline & $\mathrm{OR}$ & $95 \% \mathrm{Cl}$ & $\boldsymbol{p}$ value & $\mathrm{OR}$ & $95 \% \mathrm{Cl}$ & $\boldsymbol{p}$ value \\
\hline Sex (\% female) & 2.88 & $1.25-6.66$ & $0.011^{*}$ & 3.60 & $1.32-9.83$ & $0.013^{*}$ \\
\hline ISN/RPS III or IV, \% & 0.53 & $0.29-0.96$ & $0.035^{*}$ & 1.82 & $0.73-4.50$ & 0.192 \\
\hline Mixed LN & 0.27 & $0.08-0.88$ & $0.022^{*}$ & 0.18 & $0.04-0.80$ & $0.024^{*}$ \\
\hline Hemoglobin, g/dl & 1.16 & $0.99-1.35$ & 0.066 & 1.18 & $0.97-1.43$ & 0.086 \\
\hline $\mathrm{Cr}, \mathrm{mg} / \mathrm{dl}$ & 0.52 & $0.27-0.99$ & $0.031^{*}$ & 0.96 & $0.48-1.89$ & 0.900 \\
\hline Index of activity (0-24) & 0.81 & $0.73-0.91$ & $<0.001^{*}$ & 0.80 & $0.68-0.94$ & $0.007^{*}$ \\
\hline Hypertension & 0.44 & $0.24-0.81$ & $0.009^{*}$ & 0.59 & $0.28-1.22$ & 0.153 \\
\hline Early-onset LN & 1.91 & $1.05-3.49$ & $0.035^{*}$ & 2.10 & $1.05-4.23$ & $0.035^{*}$ \\
\hline
\end{tabular}

${ }^{*} p<0.05$

authors defined early-onset $\mathrm{LN}$ as the development of LN within 1 year of the onset of SLE. They reported that their early-onset LN patients achieved a better response to treatment than their late-onset patients, which is similar to our present findings.

Most cases of LN develop within 5 years of the diagnosis of SLE, with approx. 5-15\% of LN cases developing later $[2,27,28]$. There are no standardized definitions of early-onset and late-onset LN, but several studies made clinical comparisons separated by 5 years [10, 11, 17], and we followed that approach in the present work.

In our cohort, the predictors of CR after 6 and 12 months of induction therapy were female sex, proteinuria (CR attainment at 6 months only), mixed LN (CR attainment at 12 months only), index of activity (0-24), and early-onset LN. A number of LN studies have also reported that sex [29-31], proteinuria at baseline [13, 32], mixed LN [33], and index of activity (0-24) [34-36] affect

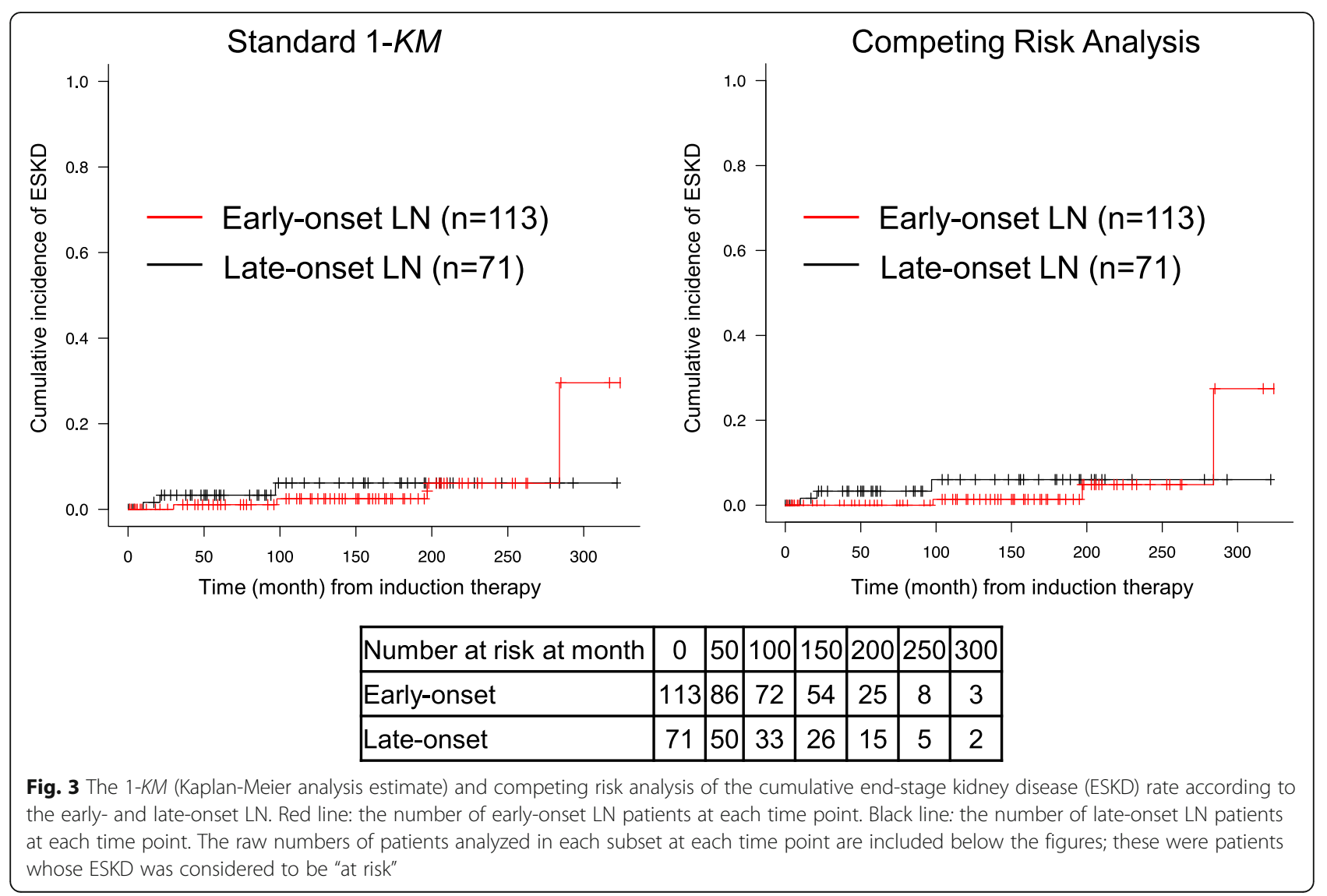




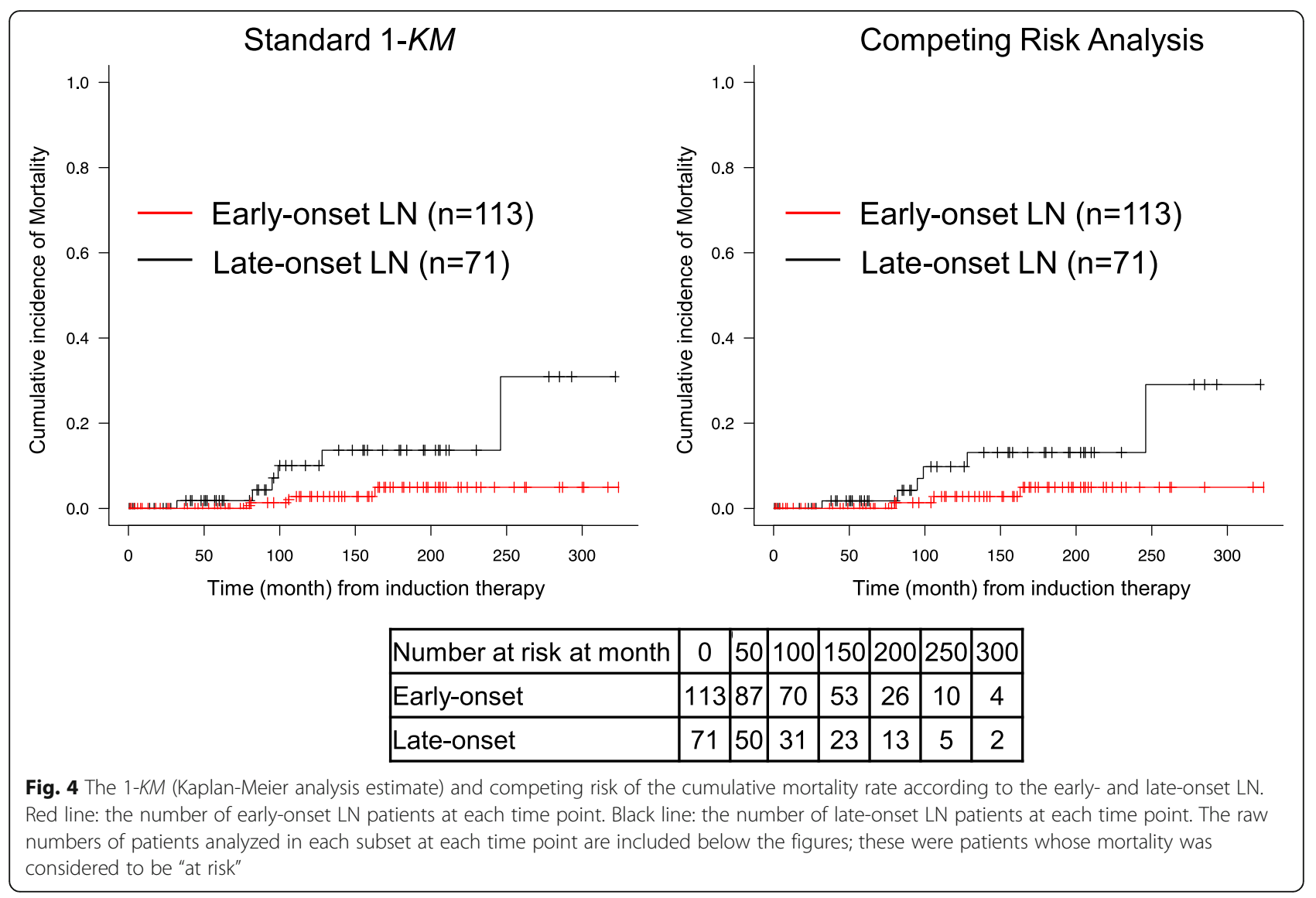

the $\mathrm{CR}$ after induction therapy. However, to date, earlyonset $\mathrm{LN}$ has not been reported to be an independent predictor of CR at 6 and 12 months.

In our cohort, the early-onset LN group was characterized by higher levels of anti-ds-DNA antibodies and hypocomplementemia with higher serological activity (Table 1), more frequent ISN/RPS class II (Fig. 2), less frequent class III/IV (Table 1) and mixed LN (Fig. 2), and a lower index of chronicity (0-12) compared to the late-onset group. We consider the possibility that the late-onset LN cases may not have been highly immunologically active compared to the early-onset LN cases, since treatment with some therapeutic agents had already started at baseline. More importantly, we suspect that this difference in attainment of a CR was observed because our early-onset LN group had more patients in ISN/RPS class II, and patients in this class are known to achieve a better response to induction therapy compared to those with class III/IV or mixed LN. Some investigators have proposed that long-term renal function was significantly affected by the baseline index of chronicity $(0-12)$ in LN patients [37, 38].

Table 4 Cox proportional hazards and Fine-Gray regression model for risk of end-stage kidney disease and mortality

\begin{tabular}{|c|c|c|c|c|c|c|}
\hline \multirow{3}{*}{ Variables } & \multicolumn{3}{|c|}{ Cox regression model } & \multicolumn{3}{|c|}{ Fine-Gray regression model } \\
\hline & \multicolumn{6}{|c|}{ End-stage kidney disease } \\
\hline & Hazard ratio & $95 \% \mathrm{Cl}$ & $p$ value & Hazard ratio & $95 \% \mathrm{Cl}$ & $p$ value \\
\hline Late-onset LN & 1 & Ref. & & 1 & Ref. & \\
\hline Early-onset LN & 0.76 & $0.17-3.90$ & 0.726 & 0.61 & $0.12-3.21$ & 0.560 \\
\hline \multirow[t]{2}{*}{ Variables } & \multicolumn{6}{|l|}{ Mortality } \\
\hline & Hazard ratio & $95 \% \mathrm{Cl}$ & $p$ value & Hazard ratio & $95 \% \mathrm{Cl}$ & $p$ value \\
\hline Late-onset LN & 1 & Ref. & & 1 & Ref. & \\
\hline Early-onset LN & 0.24 & $0.05-0.93$ & $0.038^{*}$ & 0.26 & $0.07-0.99$ & $0.043^{*}$ \\
\hline
\end{tabular}


Our present findings also showed that early-onset LN has a lower hazard ratio for mortality compared to lateonset LN (Table 4). In an earlier study, we observed that the survival rate of LN patients was significantly correlated with CR attainment at 12 months after the start of induction therapy [13]. We believe that early-onset LN has a higher $\mathrm{CR}$ attainment rate at 12 months compared to late-onset LN and that this may be associated with better mortality. The nine deaths in our cohort were due mainly to cardiovascular complications, malignancies, and infections (Suppl. Table S2). In our cohort, the duration of SLE at baseline was significantly longer in the late-onset LN group compared to the early-onset group, and the patients with late-onset LN may have had longer exposures to prednisolone and immunosuppressants. The patients' compromised conditions, vascular lesions, and other complications from long-term prednisolone and immunosuppressant treatment may have affected their mortality. However, we were not able to collect information on the patients' treatment before the diagnosis of $\mathrm{LN}$ for the present analyses.

There are some limitations of our study that deserve mention and suggest caution regarding the interpretation of the results. First, we must consider that a limitation of this type of study is that patients may have had a period of undiagnosed SLE before the diagnosis was made. Second, a selection bias for patients with LN may exist in this cohort. Since some patients with LN may have refused biopsy, the exclusion of these cases would have introduced a bias. In addition, there may have been variation in the $\mathrm{Up} / \mathrm{Ucr}$ criterion $(0.5 \mathrm{~g}$ or $1 \mathrm{~g}$ ), which is important in the decision to perform a renal biopsy, and here again patient selection bias would have occurred. Third, the difference in findings between the two nephropathologists was not insignificant, and since treatment decisions are made based on what the treating pathologist reads, this could clearly have had an impact on their results, even if the study pathologist did not directly influence the treatment. Fourth, our cohort had a long-term follow-up period, and there was a variation in the protocol for induction therapy; in particular, we were unable to enroll patients treated with hydroxychloroquine (HCQ) because HCQ for SLE patients was approved relatively recently in Japan (September 2015). The proportion of patients excluded because of HCQ use would have been greater in this study than in previous studies. Fifth, in late-onset LN, the duration of SLE is longer, and complications such as vascular damage and hypertension due to prednisolone and immunosuppressive treatment should be considered. However, we were not able to collect information on the patients' treatment before the onset of their LN. Sixth, we may not be able to entirely eliminate the impact of heterogeneity between early- and late-onset LNs on the outcomes. The definitions of early- and late-onset LNs vary among cohorts, and differences in response to treatment by ethnicity and socioeconomic status have led to a lack of consensus. It is thus necessary to conduct a larger-scale, multicenter international collaborative study to test the findings described herein.

\section{Conclusions}

We retrospectively analyzed the association between the mortality rate and the form of disease onset with a mean 10year follow-up in patients with LN. Our analyses revealed that early-onset LN, female sex, and a lower index of activity (0-24) were the factors most predictive of $\mathrm{CR}$ attainment at both 6 and 12 months. Early-onset LN was associated with better mortality compared to late-onset LN. We need to further investigate the factors that worsen treatment response and mortality in patients with late-onset LN.

\section{Supplementary information}

Supplementary information accompanies this paper at https://doi.org/10. 1186/s13075-020-02271-3.

Additional file 1: Figure S1. The attainment of a complete renal response (CR) after 6 and 12 months of induction therapy in the earlyand late-onset LN groups. ${ }^{*} p<0.05$. (PPTX $50 \mathrm{~kb}$ )

Additional file 2: Table S1. Baseline characteristics of the patients. Table S2. Causes of death.

\section{Abbreviations}

ACR: American College of Rheumatology; Anti-dsDNA: Anti-double-stranded DNA; Anti-RNP: Anti-ribonucleoprotein; Anti-Sm: Anti-Smith; APS: Antiphospholipid syndrome; AZA: Azathioprine; CR: Complete renal response; CyA: Cyclosporine; ERA-EDTA: European Renal Association-European Dialysis and Transplant Association; EULAR: European League Against Rheumatism; ISN/RPS: International Society of Nephrology/Renal Pathology Society; IVCY: Intravenous cyclophosphamide; LN: Lupus nephritis; MMF: Mycophenolate mofetil; MZR: Mizoribine; PE: Plasma exchange; PR: Partial renal response; SLE: Systemic lupus erythematosus; SS: Sjögren syndrome; TAC: Tacrolimus; Up/Ucr: Urine protein/creatinine ratio; WHO: World Health Organization

\section{Acknowledgements}

We acknowledge Professor Taguchi for contributing to the pathological assessment of patient specimens.

\section{Authors' contributions}

Drs. $\mathrm{Kl}$ and MK had full access to all of the data in the study and take responsibility for the integrity of the data and the accuracy of the data analysis. Study conception and design: KI, MK, SS, TN, and AK. Acquisition of data: KI, MK, KF, YH, NM, MT, FN, TS, RS, TK, NI, TI, HN, TO, and TN. Analysis and interpretation of data: KI, SS, SK, and MT. The authors read and approved the final manuscript.

\section{Authors' information}

Not applicable.

\section{Funding}

This work was supported by a Grant-in-Aid for Scientific Research (to K.l.; no. 17K09977), the Japan Intractable Diseases Research Foundation, and the Takeda Science Foundation.

Availability of data and materials

The collected data processed in this study are stored at the Departments of Immunology and Rheumatology, Nagasaki University Graduate School of Biomedical Sciences, Nagasaki, Japan. 


\section{Ethics approval and consent to participate}

This study was performed in accordance with the Declaration of Helsinki and was approved by the Investigation and Ethics Committee at Nagasaki University Hospital (approval nos. 12012397 and 17082129). Patients gave their informed consent to be subjected to the protocol.

\section{Consent for publication}

Not applicable.

\section{Competing interests}

The authors declare that they have no competing interests.

\section{Author details}

'Department of Immunology and Rheumatology, Division of Advanced Preventive Medical Sciences, Nagasaki University Graduate School of Biomedical Sciences, 1-7-1 Sakamoto, Nagasaki 852-8501, Japan. ${ }^{2}$ Department of Nephrology, Nagasaki University Hospital, Nagasaki, Japan. ${ }^{3}$ Clinical Research Center, Nagasaki University Hospital, Nagasaki, Japan. ${ }^{4}$ Department of Rheumatology, JCHO Isahaya General Hospital, Isahaya, Japan. ${ }^{5}$ Department of Rheumatology, Clinical Research Center, NHO Nagasaki Medical Center, Omura, Japan. ${ }^{6}$ Nagasaki Medical Hospital of Rheumatology, Nagasaki, Japan. ${ }^{7}$ Department of Internal Medicine, Sasebo City General Hospital, Sasebo, Japan. ${ }^{8}$ Department of Rehabilitation Sciences, Nagasaki University Graduate School of Biomedical Sciences, Nagasaki, Japan.

\section{Received: 13 May 2020 Accepted: 14 July 2020}

\section{Published online: 22 July 2020}

\section{References}

1. Tsokos GC. Systemic lupus erythematosus. N Engl J Med. 2011;365(22):2110-21.

2. Anders HJ, Saxena R, Zhao MH, Parodis I, Salmon JE, Mohan C. Lupus nephritis. Nat Rev Dis Primers. 2020;6(1):7.

3. Parikh SV, Almaani S, Brodsky S, Rovin BH. Update on Lupus Nephritis: Core Curriculum 2020. Am J Kidney Dis; 2020. in press.

4. Yap DY, Tang CS, Ma MK, Lam MF, Chan TM. Survival analysis and causes of mortality in patients with lupus nephritis. Nephrol Dial Transplant. 2012; 27(8):3248-54

5. Lerang K, Gilboe IM, Steinar Thelle D, Gran JT. Mortality and years of potential life loss in systemic lupus erythematosus: a population-based cohort study. Lupus. 2014;23(14):1546-52.

6. Faurschou M, Dreyer L, Kamper AL, Starklint H, Jacobsen S. Long-term mortality and renal outcome in a cohort of 100 patients with lupus nephritis. Arthritis Care Res (Hoboken). 2010;62(6):873-80.

7. Bernatsky S, Boivin JF, Joseph L, Manzi S, Ginzler E, Gladman DD, Urowitz M, Fortin PR, Petri M, Barr S, et al. Mortality in systemic lupus erythematosus. Arthritis Rheum. 2006:54(8):2550-7.

8. Hanly JG, O'Keeffe AG, Su L, Urowitz MB, Romero-Diaz J, Gordon C, Bae SC, Bernatsky S, Clarke AE, Wallace DJ, et al. The frequency and outcome of lupus nephritis: results from an international inception cohort study. Rheumatology (Oxford). 2016;55(2):252-62.

9. Tektonidou MG, Dasgupta A, Ward MM. Risk of end-stage renal disease in patients with lupus nephritis, 1971-2015: a systematic review and Bayesian meta-analysis. Arthritis Rheumatol. 2016;68(6):1432-41.

10. Varela DC, Quintana G, Somers EC, Rojas-Villarraga A, Espinosa G, Hincapie ME, McCune WJ, Cervera R, Anaya JM. Delayed lupus nephritis. Ann Rheum Dis. 2008;67(7):1044-6.

11. Ugolini-Lopes MR, Santos LPS, Stagnaro C, Seguro LPC, Mosca M, Bonfa E. Lateonset biopsy-proven lupus nephritis without other associated autoimmune diseases: severity and long-term outcome. Lupus. 2019:28(1):123-8.

12. Fanouriakis A, Kostopoulou M, Cheema K, Anders HJ, Aringer M, Bajema I, Boletis J, Frangou E, Houssiau FA, Hollis J, et al. 2019 Update of the Joint European League Against Rheumatism and European Renal AssociationEuropean Dialysis and Transplant Association (EULAR/ERA-EDTA) recommendations for the management of lupus nephritis. Ann Rheum Dis. 2020;79(6):713-23.

13. Ichinose K, Kitamura M, Sato S, Fujikawa K, Horai Y, Matsuoka N, Tsuboi M, Nonaka F, Shimizu T, Fukui S, et al. Factors predictive of long-term mortality in lupus nephritis: a multicenter retrospective study of a Japanese cohort. Lupus. 2019;28(3):295-303.

14. Houssiau FA, Vasconcelos C, D'Cruz D, Sebastiani GD, de Ramon GE, Danieli MG, Abramovicz D, Blockmans D, Cauli A, Direskeneli H, et al. The 10-year follow-up data of the Euro-Lupus Nephritis Trial comparing low-dose and high-dose intravenous cyclophosphamide. Ann Rheum Dis. 2010;69(1):61-4

15. Hochberg MC. Updating the American College of Rheumatology revised criteria for the classification of systemic lupus erythematosus. Arthritis Rheum. 1997:40(9):1725.

16. van den Berg JG, van den Bergh Weerman MA, Assmann KJ, Weening J J Florquin S. Podocyte foot process effacement is not correlated with the level of proteinuria in human glomerulopathies. Kidney Int. 2004;66(5):1901-6.

17. Delfino J, Dos Santos T, Skare TL. Comparison of lupus patients with early and late onset nephritis: a study in 71 patients from a single referral center. Adv Rheumatol. 2020;60(1):5

18. Austin HA 3rd, Muenz LR, Joyce KM, Antonovych TA, Kullick ME, Klippel JH, Decker JL, Balow JE. Prognostic factors in lupus nephritis. Contribution of renal histologic data. Am J Med. 1983;75(3):382-91.

19. Bertsias GK, Tektonidou M, Amoura Z, Aringer M, Bajema I, Berden JH, Boletis J, Cervera R, Dorner T, Doria A, et al. Joint European League Against Rheumatism and European Renal Association-European Dialysis and Transplant Association (EULAR/ERA-EDTA) recommendations for the management of adult and paediatric lupus nephritis. Ann Rheum Dis. 2012; 71(11):1771-82.

20. Hahn BH, McMahon MA, Wilkinson A, Wallace WD, Daikh DI, Fitzgerald JD, Karpouzas GA, Merrill JT, Wallace DJ, Yazdany J, et al. American College of Rheumatology guidelines for screening, treatment, and management of lupus nephritis. Arthritis Care Res (Hoboken). 2012;64(6):797-808.

21. Sprangers B, Monahan M, Appel GB. Diagnosis and treatment of lupus nephritis flares--an update. Nat Rev Nephrol. 2012;8(12):709-17.

22. Ichinose K, Kitamura M, Sato S, Eguchi M, Okamoto M, Endo Y, Tsuji S, Takatani A, Shimizu T, Umeda M, et al. Complete renal response at 12 months after induction therapy is associated with renal relapse-free rate in lupus nephritis: a single-center, retrospective cohort study. Lupus. 2019:28(4):501-9.

23. Kanda $Y$. Investigation of the freely available easy-to-use software 'EZR' for medical statistics. Bone Marrow Transplant. 2013:48(3):452-8.

24. Chen YE, Korbet SM, Katz RS, Schwartz MM, Lewis EJ, Collaborative Study G. Value of a complete or partial remission in severe lupus nephritis. Clin J Am Soc Nephrol. 2008;3(1):46-53.

25. Davidson JE, Fu Q, Ji B, Rao S, Roth D, Magder LS, Petri M. Renal remission status and longterm renal survival in patients with lupus nephritis: a retrospective cohort analysis. J Rheumatol. 2018:45(5):671-7.

26. Nakano M, Kubo K, Shirota Y, Iwasaki Y, Takahashi Y, Igari T, Inaba Y, Takeshima Y, Tateishi S, Yamashita H, et al. Delayed lupus nephritis in the course of systemic lupus erythematosus is associated with a poorer treatment response: a multicentre, retrospective cohort study in Japan. Lupus. 2019;28(9):1062-73

27. Galindo-Izquierdo M, Rodriguez-Almaraz E, Pego-Reigosa JM, Lopez-Longo FJ, Calvo-Alen J, Olive A, Fernandez-Nebro A, Martinez-Taboada V, VelaCasasempere $P$, Freire $M$, et al. Characterization of patients with lupus nephritis included in a large cohort from the Spanish Society of Rheumatology Registry of Patients With Systemic Lupus Erythematosus (RELESSER). Medicine (Baltimore). 2016;95(9):e2891.

28. Imran TF, Yick F, Verma S, Estiverne C, Ogbonnaya-Odor C, Thiruvarudsothy S, Reddi AS, Kothari N. Lupus nephritis: an update. Clin Exp Nephrol. 2016;20(1):1-13.

29. Wang YF, Xu YX, Tan Y, Yu F, Zhao MH. Clinicopathological characteristics and outcomes of male lupus nephritis in China. Lupus. 2012;21(13):1472-81.

30. Kono M, Yasuda S, Kato M, Kanetsuka Y, Kurita T, Fujieda Y, Otomo K, Horita $\mathrm{T}$, Oba K, Kondo M, et al. Long-term outcome in Japanese patients with lupus nephritis. Lupus. 2014;23(11):1124-32.

31. Moroni G, Vercelloni PG, Quaglini S, Gatto M, Gianfreda D, Sacchi L, Raffiotta $F$, Zen $M$, Costantini G, Urban ML, et al. Changing patterns in clinicalhistological presentation and renal outcome over the last five decades in a cohort of 499 patients with lupus nephritis. Ann Rheum Dis. 2018;77(9): 1318-25.

32. Moroni G, Quaglini S, Radice A, Trezzi B, Raffiotta F, Messa P, Sinico RA. The value of a panel of autoantibodies for predicting the activity of lupus nephritis at time of renal biopsy. J Immunol Res. 2015;2015:106904.

33. Ikeuchi H, Hiromura K, Kayakabe K, Tshilela KA, Uchiyama K, Hamatani H, Sakairi T, Kaneko Y, Maeshima A, Nojima Y. Renal outcomes in mixed proliferative and membranous lupus nephritis (class III/IV + V): a long-term observational study. Mod Rheumatol. 2016;26(6):908-13.

34. Yoo CW, Kim MK, Lee HS. Predictors of renal outcome in diffuse proliferative lupus nephropathy: data from repeat renal biopsy. Nephrol Dial Transplant. 2000;15(10):1604-8. 
35. Kammoun K, Jarraya F, Bouhamed L, Kharrat M, Makni S, Hmida MB, Makni H, Kaddour N, Boudawara T, Bahloul Z, et al. Poor prognostic factors of lupus nephritis. Saudi J Kidney Dis Transpl. 2011;22(4):727-32.

36. Malvar A, Pirruccio P, Alberton V, Lococo B, Recalde C, Fazini B, Nagaraja H, Indrakanti D, Rovin BH. Histologic versus clinical remission in proliferative lupus nephritis. Nephrol Dial Transplant. 2017;32(8):1338-44.

37. Chan TM, Tse KC, Tang CS, Lai KN, Li FK. Long-term outcome of patients with diffuse proliferative lupus nephritis treated with prednisolone and oral cyclophosphamide followed by azathioprine. Lupus. 2005;14(4):265-72.

38. Park DJ, Choi SE, Xu H, Kang JH, Lee KE, Lee JS, Choi YD, Lee SS. Chronicity index, especially glomerular sclerosis, is the most powerful predictor of renal response following immunosuppressive treatment in patients with lupus nephritis. Int J Rheum Dis. 2018;21(2):458-67.

\section{Publisher's Note}

Springer Nature remains neutral with regard to jurisdictional claims in published maps and institutional affiliations.

Ready to submit your research? Choose BMC and benefit from:

- fast, convenient online submission

- thorough peer review by experienced researchers in your field

- rapid publication on acceptance

- support for research data, including large and complex data types

- gold Open Access which fosters wider collaboration and increased citations

- maximum visibility for your research: over $100 \mathrm{M}$ website views per year

At $\mathrm{BMC}$, research is always in progress.

Learn more biomedcentral.com/submissions 